\title{
Aksi Sosial Real Care Bagi Masyrakat Terdampak Malnutrisi di Kabupaten Asmat
}

\author{
Fransiskus Irwan Widjaja1, Daniel Ginting ${ }^{2}$, Ronald Sianipar ${ }^{3}$, Sabar Hutagalung ${ }^{4}$, \\ Winson Simmamora ${ }^{5}$, Benteng MM Purba ${ }^{6}$ Ardi Lahagu $^{7}$, Evan Dongoran ${ }^{8}$, Candra \\ Gunawan Marisi9 \\ 1,2,3,4,5, 8, 9 Prodi Teologi, STT REAL Batam \\ ${ }^{6,7}$ Prodi PAK, STT REAL Batam \\ *irwanwidjaja.fiw@gmail.com
}

\begin{abstract}
Papua, one of the richest provinces in Indonesia, contributes the most taxes, but Papua is one of the poorest regions in Indonesia with a low Human Development index. Indicators can be seen from the level of Education and the level of Health. One of the biggest humanitarian disasters in Papua's history in 2018 was the case of malnutrition in Asmat District, in Nakai village, Pulau Tiga District and Agats City. The lack of volunteers and the large number of victims moved the PKM STT Real Batam in collaboration with volunteer doctors from GBI Myhome Tanjungpinang to go directly to help deal with malnutrition and other health treatments, as well as serve the community. The implementation method in this community service program, namely direct treatment and providing counseling, assistance to families who pay less attention to health. From the results of the evaluation with the PKM team, going directly to see the conditions and mentoring activities is very useful because in addition to knowing the level of public health and helping to provide vitamins, vitamins and other supplements, the theme also provides counseling, helps overcome social problems affected and their handling. Keywords: Malnutrition, Health Services, Mentoring, Community, Asmat
\end{abstract}

\begin{abstract}
Abstrak
Papua, salah satu propinsi terkaya di Indonesia yang menyumbang pajak terbesar, tetapi Papua adalah salah satu daerah termiskin di Indonesia dengan indeks Pembangunan manusia yang rendah. Indikator dapat dilihat dari tingkat Pendidikan dan tingkat Kesehatan. Salah satu bencana kemanusiaan yang terbesar dalam sejarah Papua di tahun 2018 adalah kasus gizi buruk di Kab Asmat, di kampung Nakai Distrik Pulau tiga dan Kota Agats. Minimnya relawan dan banyakknya korban menggerakkan PKM STT Real Batam yang menggandeng dokter relawan dari GBI Myhome Tanjungpinang untuk terjun langsung untuk membantu penanganan gizi buruk dan pengobatan kesehatan lainnya, serta melayani masyarakat. Metode pelaksanaan pada program pengabdian masyarakat ini, yaitu pengobatan langsung dan memberi penyuluhan, pendampingan keluarga keluarga yang kurang memperhatikan Kesehatan. Dari hasil evaluasi dengan team PKM, turun langsung melihat kondisi dan pendampingan kegiatan sangat berguna karena selain mengetahui tingkat Kesehatan masyarakat dan membantu memberi vitamin vitamin dan supplement lainnya, tema juga memberi penyuluhan, membantu mengatasi masalah masalah social yang terdampak dan penanganannya.

Kata Kunci: Gizi buruk, Pelayanan Kesehatan, Pendampingan, Masyrakat, Asmat
\end{abstract}

\section{PENDAHULUAN}

Wilayah Indonesia yang luas terdiri dari banyak pulau, tercatat ada 17.504 pulau dan beragam suku dan kaum. Dengan luasnya wilayah, problematika dan permasalahan seringkali sering timbul di mayarakat, salah satu nya adalah kasus gizi buruk.

Permasalahan gizi dan kesehatan merupakan permasalahan yang masih menjadi fenomena gunung es di Indonesia. Dapat dilihat di banyak kota dan provinsi masih memiliki permasalahan kesehatan yang cukup banyak. Permasalahan gizi di Indonesia terus meningkat dari tahun ke tahun. Permasalahan gizi dan kesehatan ini akan berpengaruh terhadap kesehatan bayi dan balita. Salah satu kasus adalah yang terjadi di Kabupaten Asmat Papua. 


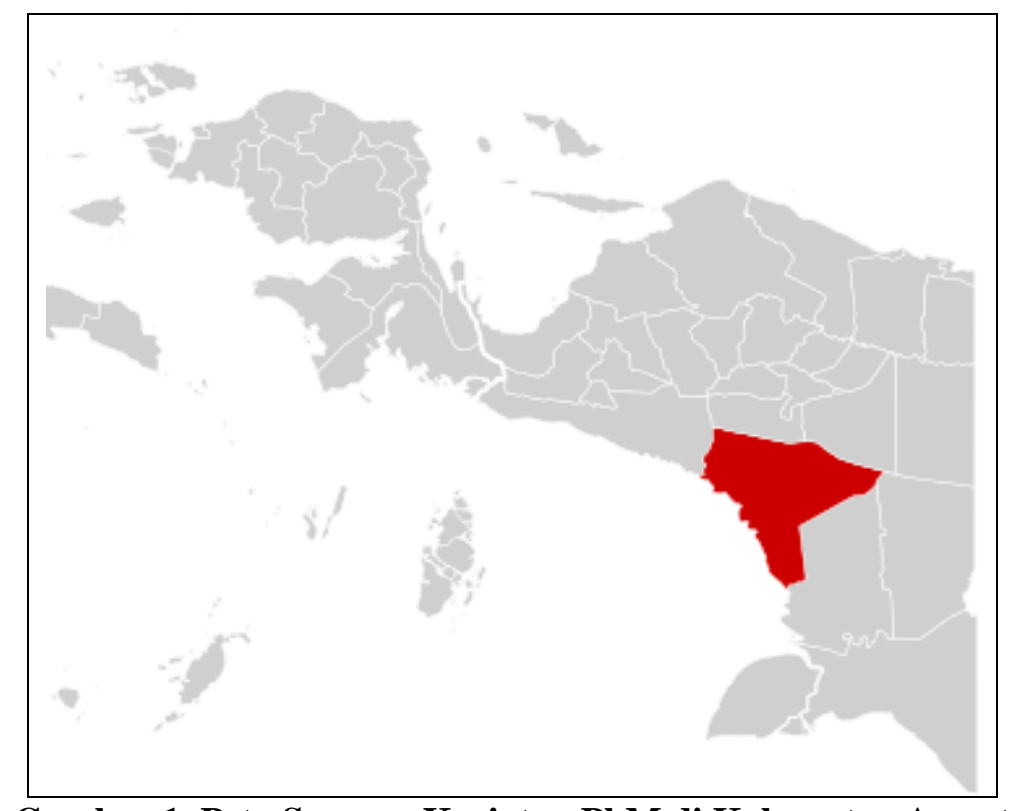

Gambar 1. Peta Sasaran Kegiatan PkM di Kabupaten Asmat

Peristiwa malnutrisi dan gizi buruk merupakan bencana kemanusiaan, terlebih lagi terjadi di jaman milenial yang mana hal hal seperti itu seharusnya bisa di atasi. Terlebih lagi, Papua adalah salah satu Provinsi penyumbang pajak terbesar di Indonesia dengan sumber kekayaan alam dan hayati yang luar biasa; mulai dari hutan, Laut bahkan tambang yang ada di perut bumi Papua. Dampak dari musibah bencana kelaparan dan gizi buruk selain berupa korban jiwa, kerusakan sosial, dan gangguan terhadap tata kehidupan serta penghidupan masyarakat.

Sampai dengan tanggal 8 Januari 2018 ini tercatat 7 balita dirawat dengan gizi buruk di RSUD, 5 diantaranya Positif Campak. Pada tanggal 9 januari 2018 tercatat di Kampung Nakai, Distrik Pulau Tiga 2 balita Meninggal dunia, dan di kota Agats tercatat 12 Kasus campak dan 7 Kasus gizi buruk, Dalam data awal yang diperoleh dari dinas kesehatan setempat berkoordinasi dengan beberapa dinas terkait maka jumlah korban yang dapat diinformasikan adalah sebanyak 9 Orang, terdiri dari 2 orang meninggal, dan akhirnya Menteri Kesehatan Nila Djuwita F Moeloek mengatakan, 71 orang meninggal akibat wabah campak dan gizi buruk di Kabupaten Asmat, Papua. "Update data, yang meninggal kurang lebih 71 orang," kata Nila seusai rapat terbatas mengenai penanggulangan Kejadian Luar Biasa (KLB) di Kabupaten Asmat, Papua, di Kantor Kemenko PMK, Jakarta, Rabu (31/1/2018).(Belarminus 2018). Melihat data yang ada, Team PKM STT Real Batam, merespon panggilan tersebut, sebagaimana Papua perlu di tolong. Program "Real Care" yang digagas oleh STT REAL Batam adalah bagian dari program Pengabdian Masyarakat STT REAL Batam yang peduli akan penderitaan sesama untuk melaksanakan tridharma perguruan tinggi.

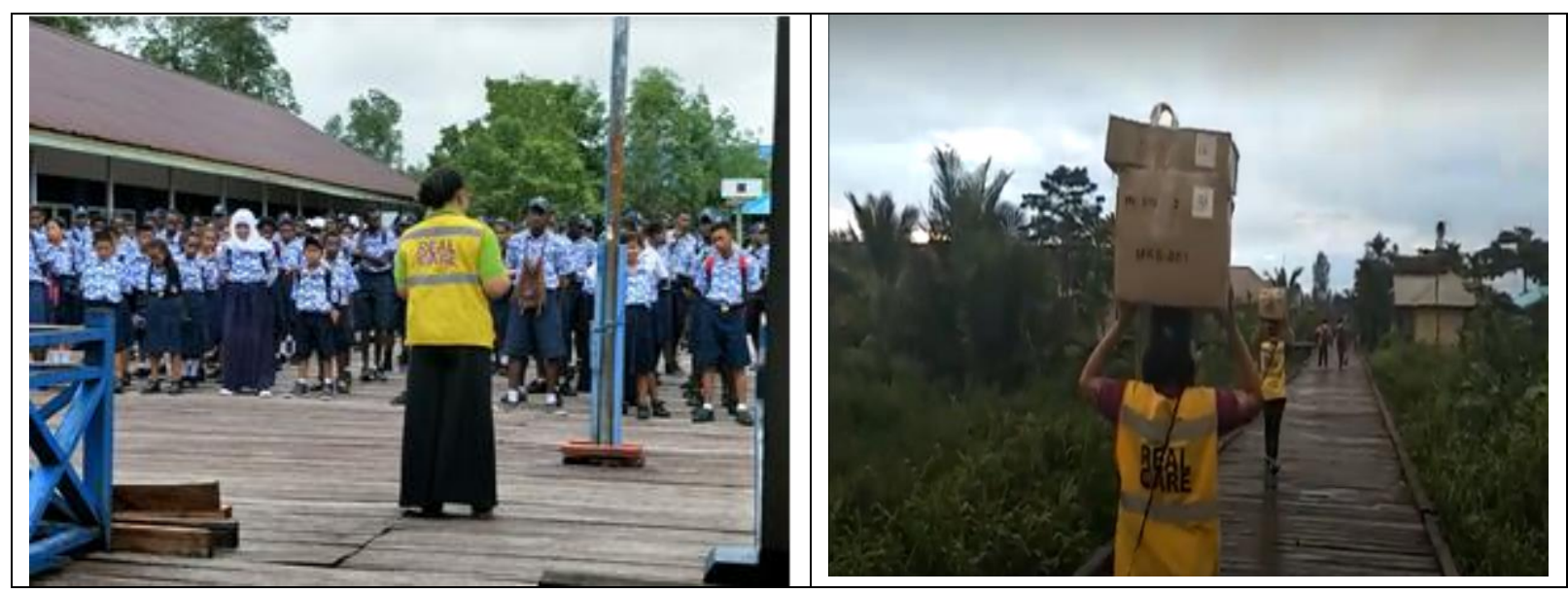




\section{Gambar 2. Penyuluhan \& Penyaluran Bantuan}

Program pengabdian masyarakat ini diharapkan dapat meringankan dan menambah pengetahuan serta wawasan masyarakat mengenai pentingnya gizi, Kesehatan ibu dan anak. Kegiatan ini dilakukan selama 5 hari, dari 23-27 Juli 2018. Rangkaian kegiatan yang dilakukan pada program ini meliputi penyuluhan, pengobatan keliling, konsultasi gizi, pengobatan dan pencabutan gigi dan memberi vitamin.

\section{Permasalahan Lapangan}

Kabupaten Asmat terletak di daerah pesisir Selatan Papua dengan luas wilayah $29.658 \mathrm{~km} 2$ yang semua wilayah terdiri dari rawa-rawa, dan dikelilingi hutan manggrove serta aliran sungaisungai. Medan yang berat dan jauh dari pusat kota. Untuk menjangkau Asmat, khususnya Agats ibukota dan kota kecamatan yang terbesar di Kabupaten ini hanya bisa melalui laut atau pesawat dari Timika. Bila menggunakan perjalanan laut, maka ditempuh dengan waktu 8 hingga 9 jam. Sedangkan dengan perjalanan udara bisa ditempuh dalam waktu 45 menit dengan pesawat kecil jenis TwinOtter dan Caravan yang berkapasitas 8-10 orang saja. Jadwal penerbangan tersebut hanya 3 kali seminggu.

Sesampainya di Bandara Ewer, perjalanan masih harus ditempuh dengan perahu menuju Agats, ibu kota Kabupaten Asmat. Perjalanan menyusuri rawa dan sungai itu ditempuh dengan waktu 30 menit. Setiap penumpang dikenakan tarif Rp 100 ribu.

Selain terkenal dengan istilah kota lumpur, Asmat juga sering dijuluki kota seribu papan. Sebab papan ini menjadi penghubung antar titik di Asmat. Nyaris seluruh kota Kabupaten dari kawasan pelabuhan hingga jantung kota semua dibangun di atas panggung lantai papan. Problem yang tidak kalah penting yang teramati oleh Tim PkMadalah rendahnya penanganan masalah gizi buruk, minimnya akses penduduk miskin terhadap pelayanan kesehatan, serta penanggulangan wabah penyakit menular, terbatasnya pelayanan kesehatan di daerah Asmat serta kekurangan SDM tenaga medis. Rasio tenaga kesehatan terhadap jumlah penduduk yang harus dilayani masih rendah. Fasilitas kesehatan belum tersebar merata dan hanya menjangkau masyarakat di pusat-pusat kota. ${ }^{1}$ Paradigma pembangunan yang topdown dan sentralistis kentara mempengaruhi kebijakan-kebijakan kesehatan pemerintah yang blueprintoriented. Hal ini menimbulkan kekeliruan pada Sistem pelayanan kesehatan yang kaku mengikuti petunjuk teknis pemerintah sementara kondisi dan lingkungan masyarakat begitu dinamis. Sayangnya, pendekatan pembangunan yang bersifat sentralistis dan bersifat uniformsulit menyentuh berbagai kebutuhan lokal yang sangat bervariasi. ${ }^{2}$

Oleh karena itu Tim PkM dari STT Real Batam menyadari akan perannya sebagaiInstitusi local yang dipandang mampu mengupayakan pelayanan kesehatan dalam agenda pengabdiannya. Tentu saja hal tersebut terwujud berkat dukungan dari berbagai pihak. Tim PkM STT Real Batam yang dimotori oleh LPPM Real Batam setiap tahun menyasar wilayah-wilayah 3T dalam mmemberikan pelayanan berupa bakti social, pengobatan, pemberian bantuan, misi kemanusiaansebagaimana sesuai dengan teori Norman Uphoff. ${ }^{3}$

Pelayanan kesehatan dalam bingkai teori fungsional struktural adalah item yang berfungsi bagi terselenggaranya kehidupan masyarakat yang tertib, seimbang dan teratur. Jika diperhatikan tatanan social seolah-olah turut mempengaruhi system social dalam hubungannya dengan Kesehatan individu. Sementara dalam perspektif teori konflik, Kesehatan dipandang sebagai bentuk power dari individu. Dengan kata lain asumsi hanya yang memiliki kekuasaan yang beruntung atas kualitas Kesehatan individu. Pada titik ekstrem dari teori ini, kesehatan menjadi representasi dari akumulasi penghasilan. Kondisi tersebut mengamini pendapat Kaplan dkk. 1996, dan Lynch dkk, 1998 bahwa ketidaksetaraan penghasilan berhubungan dengan tingkat pengeluaran untuk kesehatan. Akibat minimnya alokasi

\footnotetext{
${ }^{1}$ Puji Restiyani, Fitriyah, and Lusia Astrika, “Aksesibilitas Masyarakat Miskin Dalam Memperoleh Pelayanan Kesehatan (Studi Kasus Di Kawasan Kampung Tambak Mulyo Kelurahan Tanjung Mas Semarang," Journal of Politic and Government Studies 2, no. 3 (2013): 1-13.

${ }^{2}$ Soetomo, "Persoalan Pengembangan Institusi Masyarakat," Jurnal Ilmu Sosial dan Politik. 10, no. 1 (2006): 51-69.

${ }^{3}$ Norman Uphoff, Local Institutional Development: An Analytical Sourcebook (Connecticut: Kumarian Press, 1986).80-109
} 
biaya untuk kesehatan mempengaruhi tingkat kesehatan individu. ${ }^{4}$ Dalam asumsi dasar seperti ini factor mutlak penentu tinggi-rendahnya akses Kesehatan yang berkualitas adalah individu. Asumsi ini dibantah oleh dengan memberikan argumentasi sebaliknya individu bukanlah penyebab utama munculnya masalah kesehatan individual. ${ }^{5}$

Namun faktanya, kelas sosial berbanding lurus dengan kehidupan sosial individu tidak hanya berkaitan dengan relasi dan interaksi sosial, melainkan dengan kebutuhan hidupnya. Menurut Higgs dan Scambler salah satu elemen esensial dari kelas sosial adalah efeknya terhadap kehidupan masyarakat. ${ }^{6}$ Namun, gap spasial bukanlah faktor utama penghambat aksesibilitas masyarakat miskin pada pelayanan kesehatan. Di sini penulis setuju dengan pendapat Ferdinandus, mengenai factor internal dan eksternal yang sering menjadi kendala akses masyarakat miskin terkait pelayanan kesehatan. $^{7}$

Secara umum sistem pelayanan kesehatan masih dalam wilayah dominan pemerintah sebagai actor utama yang mempunyai legitimasi dalam pengorganisasian pelayanan Kesehatan. Demikian juga halnya kendali penyediaan pelayanan social bagi kebutuhan masyarakat masih terpusat pada pemerintah. Sementara pelayanan sosial seyogiyanya dimaknai sebagai aktivitas produksi, pengalokasian dan pendistribusian sumberdaya sosial kepada public. ${ }^{8}$

\section{Sumber Dana}

Usulan dana pengabdian diajukan pada SekolahTinggi Teologi REAL Batam dengan Mitra Indonesia Cerdas, sumbangan siswa, bantuan gereja, sumbangan pribadi. Diharapkan melalui program pastoral konseling, konseling trauma dan mendoakan serta membantu membangun rumah sementara dan mengutus guru guru alumni STT Real Batam, baik jurusan PAK maupun Theologi. Di harapkan bantuan total secara holistic dapat meringankan beban penderitaan masyarakat sekaligus menjangkau yang belum "percaya" dengan kasih Kristus. Pelayanan ini juga mendukung program pemerintah dalam masa tanggap darurat dan masa pemulihan. Pelayanan yang di berikan dapat menyentuh dan membangun nilai-nilai kehidupan, sehingga dapat memperlengkapi warga secara jasmani dan rohani.

\section{Tujuan Kegiatan}

a. Membantu warga yang mengalami gizi buruk dan membantu pengobatan secara langsung mendatangkan dokter serta ahli medis.

b. Memberikan semangat dan motivasi dengan memberi penyuluhan terkait kesehatan

c. Membantu secara finansial,makanan serta pakaian

d. Mengutus guru guru untuk mengajar di sekolah maupun di luar jam sekolah

\section{Manfaat Kegiatan}

Kegiatan PKM STT Real Batam, untuk membantu kelompok masyarakat yang terdampak secara eknonomi yang memiliki kebutuhan hidup yang harus terpenuhi. Manfaat dari kegiatan ini adalah agar masyarakat sehat.

Menurut LP Getubig dan Schmidt, income, Kesehatan (health care), Asupan gizi (Good nutrion), air bersih dan Pendidikan dan sanitasi yang baik adalah kebutuhan dasar manusia yang hakiki yang mana manusia akan merasa aman.

\footnotetext{
${ }^{4}$ Kevin White, Pengantar Sosiologi Kesehatan Dan Penyakit, 3rd ed. (Jakarta: Rajawali Press, 2011). 102

${ }^{5}$ William C Cockerham, Medical Sociology, 5th ed. (New Jersey: Prentice-Hall: Englewood Cliffs, 1992).260

${ }^{6}$ Graham Scambler and Paul Higgs, Explaining Health Inequalities :How Useful Are Concepts of Social Class? In Modernity, Medicine and Health (London: Routledge, 1998).6

${ }^{7}$ Ferdinandus, “Akses Masyarakat Miskin Terhadap Pelayanan Kesehatn Di Kabupaten Bolaang Mongondow” (Universitas Gadjah Mada, 2008).33

8 Janianton Damanik, "Menuju Pelayanan Sosial Yang Berkeadilan," Jurnal Ilmu Sosial dan Ilmu Politik 15, no. 1 (2011): 1-14.
} 


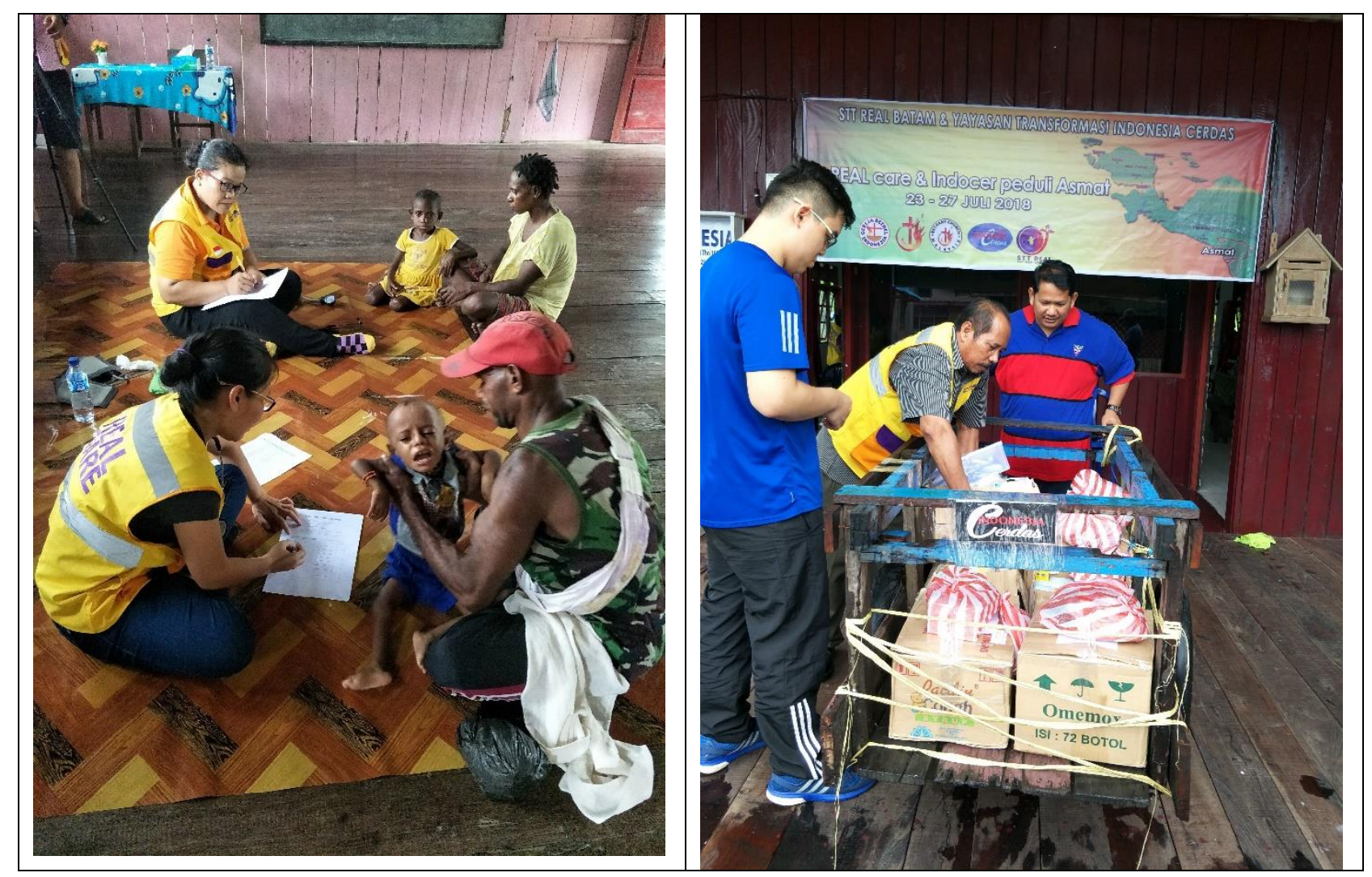

Gambar 3. Pelayanan Kesehatan \& Pengecekan Obat-obatan

Tahapan Kegiatan

Tahap-tahap yang dilaksanakan dalam kegiatan ini:

a. Tahap Sosialisasi, tahap ini dimulai dengan mengenal karakter dari kelompok sasaran sehingga akan memudahkan dalam melaksanakan program yang direncanakan agar individuindividu dalam kelompok pada program ini mampu bangkit dan percaya diri pulih.

b. Tahap Pendampingan pada tahap ini, kelompok didampingi untuk dapat menjalankan kegiatan dengan pastoral care di sertai dengan pengertian

c. Tahap pemantauan pasca kegiatan, yang bertujuan untuk melihat pertumbuhan pemulihan para pengungsi dan korban

\section{Metode Penelitian}

Berdasarkan masalah yang dikemukakan tersebut di atas, maka Tim pengabdian kepada masyarakat (abdimas) melakukan penelitian singkat. Penelitian ini bersifat deskriptif kualitatif, dilaksanakan di kabupaten Asmat khususnya Agats. Pengumpulan data dilakukan dengan wawancara lisan dampak sosial psikologis warga miskin. Observasi tentang kondisi dan analisa dokumen dan pemetaan yang terkait dengan kondisi wilayah dan jumlah masyrakat miskin. Selanjutnya data yang terkumpul dianalisis secara deskriptif kualitatif. Langkah Analisa sebagai berikut:

1. Pada tahap pertama untuk pemecahan masalah terbatasnya rasa minder dan kekuatiran akan kondisi kesehatan. Untuk meningkatkan pengetahuan maupun percaya diri mereka, serta untuk meningkatkan pemberdayaan diri sehingga ada kegairahan dalam bentuk pemberdayaan maka Tim merencanakan pendekatan berupa penyuluhan, Konsultasi dan mendoakan.

2. Tahap ketiga, untuk membangun sikap untuk meningkatkan percaya diri, bagi mereka yang kehilangan pekerjaan dilakukan dengan diskusi, tanya jawab dan mencari solusi berbagai kendala saat itu yang sering mereka alami berkaitan dengan kondisi di Kabupaten Asmat. 


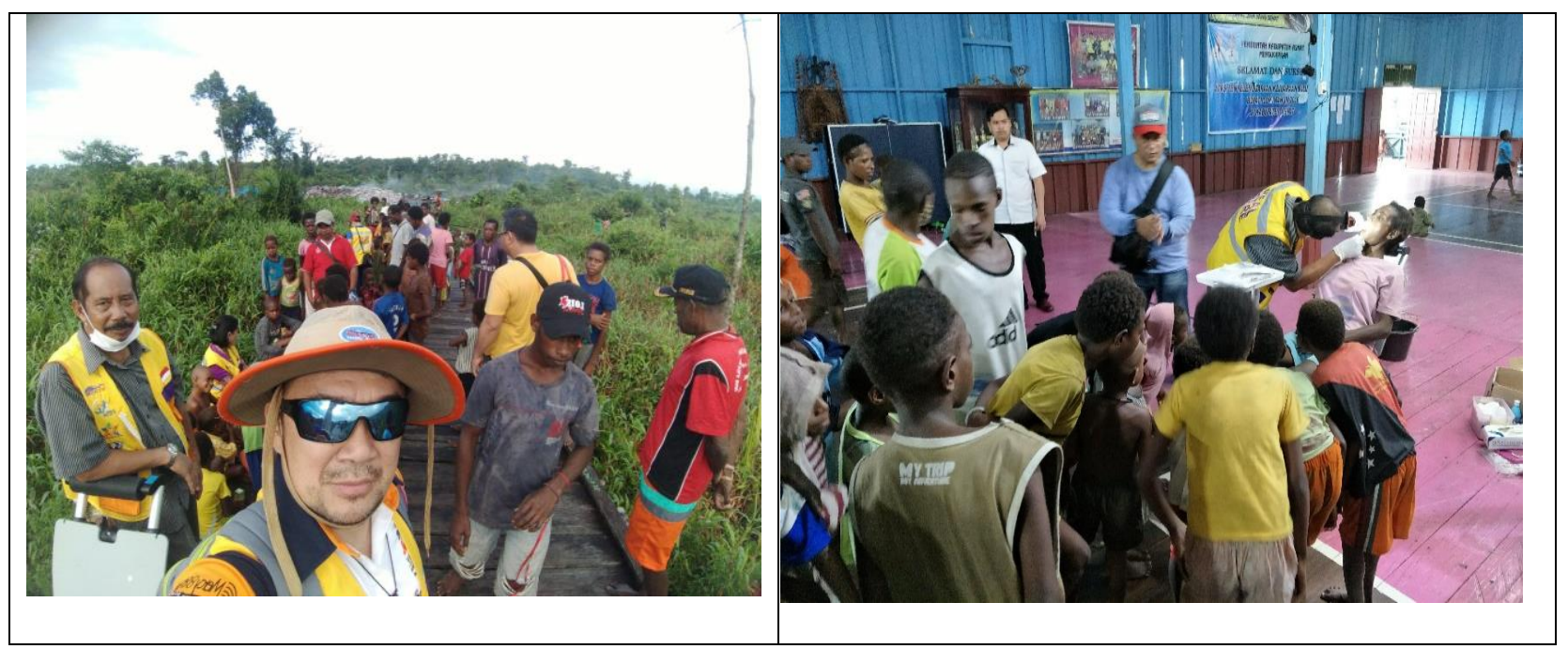

Gambar 4. Foto Bersama Tim Relawan, dokter \& Pemeriksaan Kesehatan

\section{Metode Pelaksanaan}

Metode pelaksanaan pada program pengabdian masyarakat ini,

\begin{tabular}{|l|l|l|l|l|l|l|}
\hline \multirow{2}{*}{ No } & \multirow{2}{*}{ Uraian Kegiatan } & \multicolumn{5}{|c|}{ Waktu 2018 } \\
\cline { 3 - 7 } & & Jun & Jul & Agu & Set & Okt \\
\hline 1 & Pendataan Keluhan sakit warga & & & & & \\
\hline 2 & Pengecekan Kesehatan & & & & & \\
\hline 3 & $\begin{array}{l}\text { Pelayanan Tim Medis \& } \\
\text { Konsultasi kesehatan }\end{array}$ & & & & & \\
\hline 4 & Pemberian Makan Bergizi & & & & & \\
\hline 5 & Penarikan seluruh team & & & & & \\
\hline
\end{tabular}

Berdasarkan pengamatan dan wawancara observasi lapangan yang telah diuraikan diatas, bahwa terdapat permasalahan sebagai berikut:

Beberapa permasalahan yang dihadapi korban bencana yaitu:

1. Kehilangan jiwa kanak kanak.

2. Kehilangan semangat dan gairah karena kematian anak anak.

3. Pemenuhan kebutuhan dasar berupa makan, minum, tempat tinggal, pendidikan, kesehatan dan sarana air bersih yang tidak memadai.

4. Terganggunya pendidikan anak-anak yang tidak bisa sekolah karena tidak ada guru

5. Timbulnya berbagai penyakit-penyakit (batuk, flu), penyakit busung lapar dan kurang gizi

6. Pudarnya harga diri dan kapabilitas yang baik sebagai individu maupun sebagai keluarga karena tidak dapat menolong anak anak yang mereka kasihi

7. Timbulnya perasaan frustasi terhadap waktu yang tidak pasti, perasaan tidak berdaya, ketakutan dan bahkan perasaan putus asa menghadapi kemungkinan terburuk ke depan. Akhirnya mengakibatkan marah, stres, dan frustasi terhadap keadaan yang serba tidak menentu, trauma, putus asa, merasa tidak berdaya dan ketidakpastian terhadap masa depannya.

\section{Hasil Pembahasan}

Dari kegiatan pengabdian masyarakat melalui PkM. Dari 20 orang anggota team yang terdiri dari dosen, medical dokter yang di bagi empat group, secara maksimal mengerjakan hal hal di lapangan di dapati sebagai berikut:

Kegiatan pengabdian masyarakat PKM Real Care dan peduli asmat dalam penanganan Korban gizi buruk, khususnya masyarakat asmat memerlukan berbagai kebutuhan agar dirinya dapat bertahan hidup dan bangkit kembali. Untuk itu, hal-hal di bawah ini perlu di perhatikan: 
1. Penanganan Dampak Sosial Psikologis.

Permasalahan nyata yang dialami keluarga keluarga korban gizi buruk akibat pengobatan yang berkepanjangan dan ada keluarga yang meninggal

2. Pemenuhan kebutuhan fisik

Kebutuhan fisik merupakan masalah utama yang memerlukan bantukan, seperti makan, minum dan tempat tinggal yang layak aman. Pentingnya pemenuhan kebutuhan fisik ini dikarenakan penduduk yang tinggal di daerah gizi buruk sangat minim air bersih dan sanitasi rumah tangga.

3. Pemenuhan kebutuhan psikis

Perasaan Sedih yang dialami yang disebakan karena kehilangan keluarga yang mereka sayangi, dapat mengakibatkan timbulnya gangguan psikologis. Sehingga selain kebutuhan fisik, hal yang tidak kalah penting adalah pemenuhan kebutuhan psikis.

4. Pemenuhan kebutuhan social

Situasi dan kondisi kehidupan yang mereka alami memunculkan perasaan kecewa dan putus asa bahkan frusterasi karena ketidakjelasan dengan nasib mereka dan bantuan baik dari pemerintah maupun masyarakat di luar asmat

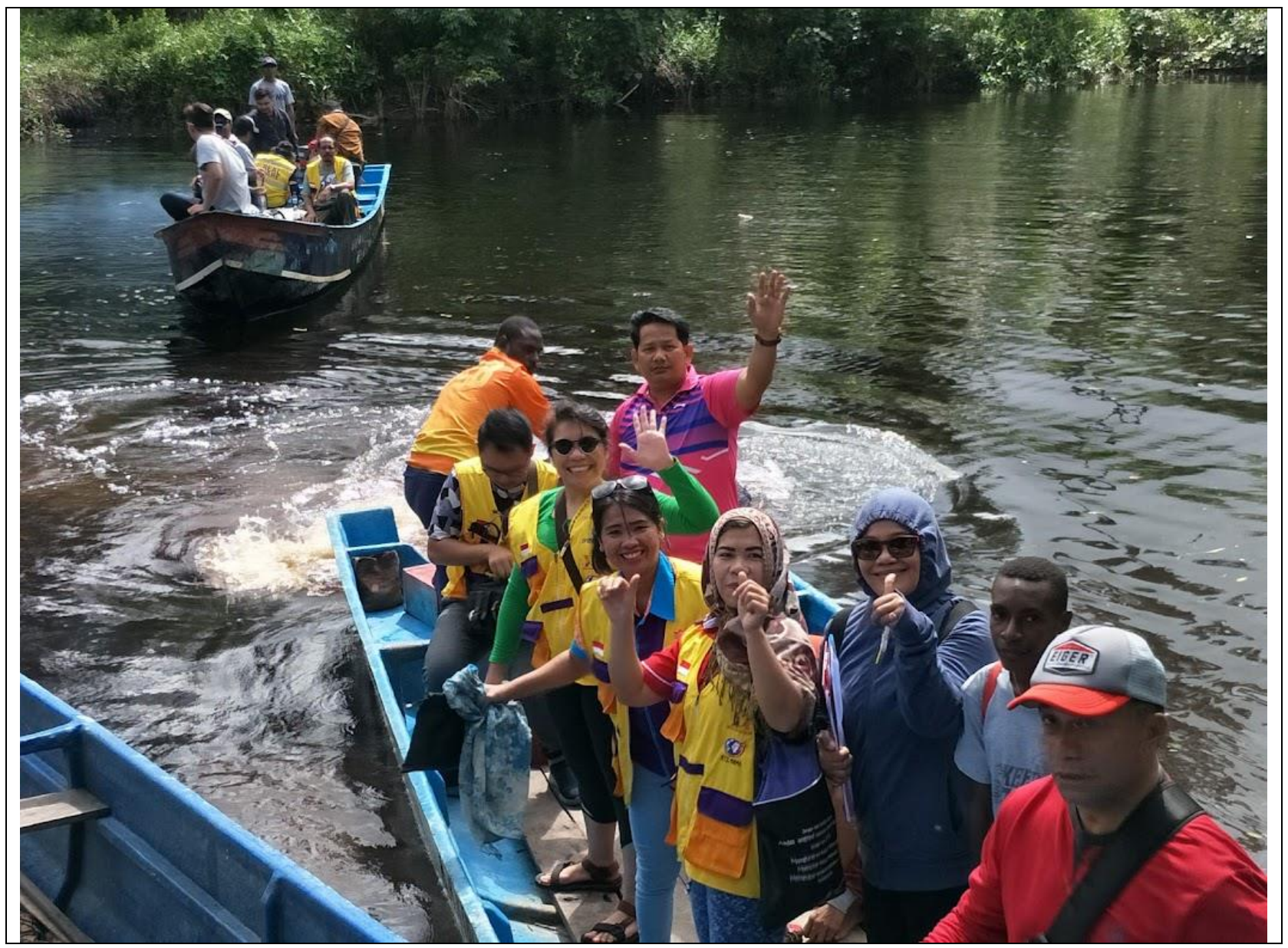

Gambar 5. Team Relawan direlokasi ke distrik lain

Kebutuhan pangan, pakaian, shelter, fasilitas kesehatan. Berbagai kegiatan penyuluhan dan pemeriksaan kesehatan juga dilakukan yang melibatkan khalayak umum,

Aksi Pelayanan melibatkan tiga hal pokok, yaitu:

a. Penyuluhan Kesehatan dan kebersihan lingkungan

b. Menggandeng Pelibatan Pemerintah setempat

Dalam Widjaja, ${ }^{9}$ untuk dapat mempengaruhi kebijakan pemerintah dalam hal ini, masyarakat dapat

${ }^{9}$ Fransiskus Irwan Widjaja, "Peran Gereja Terhadap Kehidupan Politik Di Wilayah Kepulauan Riau," Real Didache 1, no. 2 (2016): 117-140. 
menilai dan merasakan suatu kehidupan yang lebih baik; misalnya: tersedianya lapangan pekerjaan, perbaikan gizi, dan berkurangnya tingkat kemiskinan. Pengambil keputusan mempunyai kompetensi dalam sektor keamanan, sistem ekonomi, penyediaan akses lembaga keuangan, fasilitas informasi, kesehatan, kesejahteraan sosial, layanan administrasi kependudukan, dan penyediaan sarana sekolah formal. Kebijakan dan perencanaan pemerintah berperan untuk mencegah persoalan yang berlanjut, seperti sakit berkepanjangan, kekurangan gizi, frustrasi, perilaku negatif, pemiskinan, stunting, dan ketertinggalan sebagai dampak dari lingkungan di Kabupaten Asmat tanpa intervensi dari pihak pengambil kebijakan pemerintah. Hal ini dimaksudkan untuk mencegah peluang terjadinya masyarakat yang dimarginalkan, sosial cost atau generation lost.

c. Aksi Pelayanan Kesehatan LPPM Bersama Indonesia Cerdas

Dalam masyarakat golongan miskin, aksi ini dijalankan dengan menjunjung tinggi prinsip partisipasi, dimulai dari penyusunan rencana, identifikasi masalah, penetapan skala prioritas, tujuan, implementasi dan pemantauan, serta evaluasi akhir dalam proses pelayanan kesehatan. Program pelayanan Kesehatan bagi warga miskin ini tentu tidak akan dapat tercapai secara maksimal apabila hanya dilaksanakan dalam satu kali program, akan lebih baik apabila dilaksanakan secara berkala. Pelayanan Kesehatan warga miskin tidak cukup dilakukan pemerintah saja, tetapi harus melibatkan pihak lain seperti swasta, lembaga lembaga social serta masyarakat lingkungan di mana warga miskin berada, baik secara perorangan maupun terorganisir yang bekerja sama atas nama kemanusiaan. Unsur pelayanan sosial pokok yang harus dilakukan bersama seperti pemenuhan kebutuhan makan, kesehatan, pakaian, sedangkan unsur penunjang meliputi publikasi, simpati masyarakat lingkungan dan konsultasi dan memotivasi warga miskin untuk hidup penuh semangat dan bijaksana. Oleh karena itu STT Real Batam dalam hal ini bermitra dengan Yayasan Indonesia Cerdas.

Langkah yang dilakukan dalam upaya Pelayanan Kesehatan warga miskin antara lain:

a. Penyuluhan Kesehatan

b. Pendekatan proaktif artinya tidak menunggu adanya masalah, tetapi mencari masalah. Petugas kesehatan dan Tim relawan tidak hanya menunggu pasien datang ke kantor atau di tempat praktik mereka, tetapi harus turun ke masyarakat untuk mencari dan mengidentifikasi masalah yang ada di masyarakat, dan selanjutnya melakukan tindakan jika diperlukan

c. Pasien dilihat sebagai makhluk yang utuh sehingga terjadinya penyakit tidak semata-mata karena terganggunya sistem biologi, individual, tetapi dalam konteks yang luas, aspek biologis, psikologois, dan sosial. Dengan demikian pendekatannya harus secara menyeluruh atau holistik Membangun partisipasi.

d. Mediasi dan fasilitasi Kesehatan dibarengi dengan penyuluhan kepada masyarakat mengenai edukasi pola hidup sehat

\section{KESIMPULAN}

Kegiatan pengabdian masyarakat PKM Pelayanan kesehatan, khususnya warga miskin memerlukan berbagai kebutuhan kesejahteraan baik secara fisik maupun psikis agar semangat hidup Kembali bangkit. Untuk itu, hal-hal di bawah ini perlu di perhatikan: 1) Permasalahan nyata yang dialami warga yang tinggal di Kabupaten Asmat adalah, melemahnya semangat kemasyarakatan karena lingkungan yang kurang mendukung untuk hidup sehat dan sejahtera, 2) Kebutuhan fisik warga miskin yang berada di Kabupaten Asmat yang mengalami masalah gizi buruk, kekurangan makanan bergizi, kekurangan sumber air bersih dan lingkungan tempat tinggal yang ideal, 3) Pembinaan \& Penyuluhan tentang Pendidikan akibat rendahnya indeks pembangunan manusia di kabupaten Asmat.

\section{DAFTAR PUSTAKA}

Cockerham, William C. Medical Sociology. 5th ed. New Jersey: Prentice-Hall: Englewood Cliffs, 1992.

Damanik, Janianton. "Menuju Pelayanan Sosial Yang Berkeadilan." Jurnal Ilmu Sosial dan Ilmu Politik 15, no. 1 (2011): 1-14.

Ferdinandus. "Akses Masyarakat Miskin Terhadap Pelayanan Kesehatn Di Kabupaten Bolaang Mongondow.” Universitas Gadjah Mada, 2008. 
Prasetyo, Eko. Orang Miskin Dilarang Sakit. Yogyakarta: Resist Book, 2007.

Restiyani, Puji, Fitriyah, and Lusia Astrika. "Aksesibilitas Masyarakat Miskin Dalam Memperoleh Pelayanan Kesehatan (Studi Kasus Di Kawasan Kampung Tambak Mulyo Kelurahan Tanjung Mas Semarang." Journal of Politic and Government Studies 2, no. 3 (2013): 1-13.

Scambler, Graham, and Paul Higgs. Explaining Health Inequalities :How Useful Are Concepts of Social Class? In Modernity, Medicine and Health. London: Routledge, 1998.

Soetomo. "Persoalan Pengembangan Institusi Masyarakat." Jurnal Ilmu Sosial dan Politik. 10, no. 1 (2006): 51-69.

Uphoff, Norman. Local Institutional Development: An Analytical Sourcebook. Connecticut: Kumarian Press, 1986.

White, Kevin. Pengantar Sosiologi Kesehatan Dan Penyakit. 3rd ed. Jakarta: Rajawali Press, 2011.

Widjaja, Fransiskus Irwan. "Peran Gereja Terhadap Kehidupan Politik Di Wilayah Kepulauan Riau." Real Didache 1, no. 2 (2016): 117-140. 